\title{
Socioeconomic disparity in cervical cancer screening among Korean women: 1998-2010
}

\author{
Minjee Lee ${ }^{1}$, Eun-Cheol Park², Hoo-Sun Chang ${ }^{2}$, Jeoung A Kwon ${ }^{1}$, Ki Bong Yoo ${ }^{1}$ and Tae Hyun Kim³*
}

\begin{abstract}
Background: Cervical cancer is the sixth most common cause of cancer among Korean women and is one of the most preventable cancers in the world. This study aimed to investigate the change in cervical cancer screening rates, the level of socioeconomic disparities in cervical cancer screening participation, and whether there was a reduction in these disparities between 1998 and 2010.
\end{abstract}

Methods: Using the Korean Health and Nutrition Examination Survey, women 30 years or older without a history of cervical cancer and who completed a health questionnaire, physical examination, and nutritional survey were included $(n=17,105)$. Information about participation in cervical cancer screening was collected using a self-administered questionnaire. Multiple logistic regression analysis was performed to investigate the relationship between cervical cancer screening participation and the socioeconomic status of the women.

Results: The cervical cancer screening rate increased from 40.5\% in 1998 to 52.5\% in 2010. Socioeconomic disparities influenced participation, and women with lower educational levels and lower household income were less likely to be screened. Compared with the lowest educational level, the adjusted odds ratios (ORs) for screening in women with the highest educational level were 1.56 (95\% confidence interval (Cl): 1.05-2.30) in 1998, and 1.44 (95\% Cl: 1.12-1.87) in 2010. Compared with women with the lowest household income level, the adjusted ORs for screening in women with the highest household income level were 1.80 (95\% Cl: 1.22-2.68), 2.82 (95\% Cl: 2.01-3.96), and 1.45 (95\% Cl: 1.08-1.94) in 2001, 2005, and 2010, respectively.

Conclusion: Although population-wide progress has been made in participation in cervical cancer screening over the 12-year period, socioeconomic status remained an important factor in reducing compliance with cancer screening.

Keywords: Cervical cancer, Screening, Socioeconomic status, Disparity

\section{Background}

Cervical cancer is one of the most preventable cancers in the world but it is the eighth leading cause of cancerrelated deaths in Korea [1,2]. Regular Papanicolaou (Pap) tests are an excellent diagnostic tool for detecting not only cancerous, but also precancerous cells, both of which can be removed [3-5]. Previous observational studies have consistently shown dramatic reductions in the cervical cancer mortality rate after the implementation of population-based screening programs [6,7].

Since its introduction in the 1940s, the Pap smear has been associated with sharp declines in cervical cancer incidence and mortality $[8,9]$. In Korea, the age-adjusted

\footnotetext{
* Correspondence: thkim@yuhs.ac

${ }^{3}$ Graduate School of Public Health, Institute of Health Services Research,

College of Medicine, Yonsei University, Seoul, Korea

Full list of author information is available at the end of the article
}

incidence of cervical cancer dropped from 18.6 (per 100,000 ) in 1999 to 12.0 in 2009, and its mortality declined from6.2 per 100,000 in 1995 to 3.8 per 100,000 in $2009[1,10]$.

In Korea, there are currently three main cancer screening programs [10], namely the National Cancer Screening Program (NCSP), the Korea National Health Insurance (NHI) program, and screening services voluntarily provided by independent medical facilities. In 1999, the Korean government created the NCSP and established a 10-year plan for cancer control [11]. The NCSP provided free cancer screening services for stomach, breast, and cervical cancers to medical aid recipients between 1999 and 2001 [12]. In 2002, coverage of free cancer screening was expanded to NHI beneficiaries within the lowest $20 \%$ income bracket, and in 2003, those within the lowest 30\%

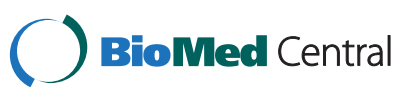

(C) 2013 Lee et al.; licensee BioMed Central Ltd. This is an Open Access article distributed under the terms of the Creative Commons Attribution License (http://creativecommons.org/licenses/by/2.0), which permits unrestricted use, distribution, and reproduction in any medium, provided the original work is properly cited. 
income bracket were included in the target population. From 2005, the NCSP expanded coverage of free screening for stomach, breast, cervical, liver and colorectal cancer to Medical Aid recipients, and the NHI included beneficiaries who were within the lower $50 \%$ of income earners [13].

Despite these public health efforts, the rate of cervical cancer screening may not be uniform across groups with different socioeconomic status. Previous studies suggested that socioeconomic disparities existed in cancer screening rates $[14,15]$, and, in particular, global evidence suggested that the cervical cancer screening rate was influenced by socioeconomic factors as well as demographic factors such as race [16-21]. Studies in the United States and Korea also showed that socioeconomic disparities continued in cervical cancer screening participation, though there has been an improvement in overall screening rate $[14,22]$.

Although the above-mentioned studies are informative in identifying important factors influencing cervical cancer screening, they are either cross-sectional studies or not nationally representative, or their study periods were in the late 1990 s or the early 2000s. To achieve timely and challenging objectives in public health, such as improvement in cancer screening rates with a reduction in socioeconomic disparities, it is necessary to monitor the long-term trend. Therefore, the objective of this study was to investigate the changes in cervical cancer screening rate over the 12-year period from 1998 to 2010 in a nationally representative sample of Korean women, and to examine whether socioeconomic disparities in cervical cancer screening rates have been reduced over this period.

\section{Methods}

\section{Data source and subjects}

This study used data from the 1998-2010 Korea National Health and Nutrition Examination Survey (KNHANES). The KNHANES is a nationally-representative study managed by the Korean Ministry of Health and Welfare. Participants were enrolled from the household registry using a stratified multistage probability design. The KNHANES consists of four parts: a health interview survey, a health behavior survey, a physical examination, and a nutritional survey. Trained interviewers conducted all surveys and trained healthcare professionals conducted all physical examinations. All participants provided informed consent before participation in the KNHANES.

There were 211,116 women aged 30 years or older who completely answered the health behavior survey between 1998 and 2010. Women who did not provide information about cervical cancer screening or nutrition or who did not have an additional physical examination were excluded from the study. Finally, a total of 17,105 women $(2,725$ in $1998,1,622$ in $2001,2,596$ in $2005,2,944$ in 2008 , and 2,737 in 2010) were included in the analysis.

\section{Independent variables and outcome variables}

From 1998 to 2001, participants were asked, "Have you ever been screened for cervical cancer?" and answers were recorded as either yes or no. From 2005 to 2010, participants were asked, "When was the last time you were screened for cervical cancer?" and answers were recorded as either never, less than 1 year ago, 1-2 years ago, or more than 2 years ago. According to the Korean NCSP guidelines, women 30 years of age and older should receive a Pap smear test every 2 years. In the present study, the outcome variable was whether participants adhered to the Korean NCSP guidelines. We defined participants as not adhering to the NCSP guidelines if they reported never being screened for cervical cancer or were examined more than 2 years prior to completing the questionnaire.

Based on a literature review, we chose several variables as possible factors related to screening participation. Thus, our primary variables of interest were socioeconomic factors, including education, household income, and occupation. Other variables included in the study were age, marital status, health insurance type, health status (limitation in general activities and perceived health status), and health behavior (smoking and obesity). Educational status was divided into three groups: none or elementary school, middle school to high school, and university or higher. Household income, provided by the KNHANES, was calculated by dividing the monthly household income by the square root of the household size, and grouped into four household income quartiles. Occupation was categorized as "white collar (manager, professional level, office workers, service workers, sales)", "blue collar (agriculture, fishery, technicians, mechanics, assemblers, simple labor)", and "others (student, housewife, unemployed)". Marital status was "married" vs. "not married". Health insurance type was categorized as national health insurance for the self-employed, national health insurance for those not self-employed, and being in receipt of Medical Aid. Health status and health behavioral factors included limitation in general activities (yes, no), perceived health status (good or regular vs. bad), smoking (non, ex or current), and body mass index (BMI), categorized as $<18.5$, $18.5-<23,23-<25$, and $\geq 25 \mathrm{~kg} / \mathrm{m}^{2}$ according to the guidelines provided by the World Health Organization West Pacific Region (2000).

\section{Statistical analysis}

The KNHANES was based on a complex sample design. Therefore, all statistical analyses were performed using the survey procedure of SAS version 9.2 (SAS Inc., Cary, NC, USA), specifically designed to analyze such sample survey results. In the survey procedure, information pertaining to complex sample designs such as stratification, clustering, and unequal weighting is combined to analyze the parameters. 
Table 1 Basic characteristics of the study population and participation rate in cervical cancer screening in women $\geq 30$ years, $1998-2010$

\begin{tabular}{|c|c|c|c|c|c|c|c|c|c|c|c|c|c|c|c|c|c|c|c|c|c|c|c|c|c|}
\hline \multirow[t]{2}{*}{ Variables } & \multicolumn{5}{|l|}{1998} & \multicolumn{5}{|l|}{2001} & \multicolumn{5}{|l|}{2005} & \multicolumn{5}{|l|}{2008} & \multicolumn{5}{|l|}{2010} \\
\hline & Total & $\%$ & Screen & $\%$ & $\begin{array}{l}\mathrm{p}- \\
\text { value }\end{array}$ & Total & $\%$ & Screen & $\%$ & $\begin{array}{l}\mathrm{p}- \\
\text { value }\end{array}$ & Total & $\%$ & Screen & $\%$ & $\begin{array}{l}\mathrm{p}- \\
\text { value }\end{array}$ & Total & $\%$ & Screen & $\%$ & $\begin{array}{l}\mathrm{p}- \\
\text { value }\end{array}$ & Total & $\%$ & Screen & $\%$ & $\begin{array}{l}\mathrm{p}- \\
\text { value }\end{array}$ \\
\hline \multicolumn{26}{|l|}{ Age (years) } \\
\hline 30-39 & 715 & 30.1 & 362 & 50.9 & $<.0001$ & 369 & 23.6 & 191 & 50.6 & $<.0001$ & 710 & 29.7 & 362 & 51.3 & $<.0001$ & 707 & 26.4 & 363 & 51.8 & $<.0001$ & 617 & 24.1 & 317 & 51.9 & $<.0001$ \\
\hline $40-49$ & 641 & 24.9 & 358 & 55.9 & & 373 & 23.8 & 217 & 58.8 & & 709 & 27.7 & 421 & 59.0 & & 663 & 28.1 & 393 & 60.2 & & 556 & 26.6 & 340 & 61.1 & \\
\hline 50-59 & 557 & 18.5 & 219 & 39.0 & & 310 & 20.1 & 132 & 43.9 & & 469 & 17.5 & 217 & 44.1 & & 562 & 20.6 & 312 & 54.3 & & 623 & 22.3 & 385 & 60.8 & \\
\hline 60-69 & 497 & 15.6 & 101 & 21.6 & & 315 & 18.3 & 79 & 26.3 & & 397 & 13.1 & 123 & 34.2 & & 536 & 13.4 & 208 & 40.7 & & 502 & 13.6 & 250 & 49.1 & \\
\hline $70+$ & 315 & 11.0 & 25 & 6.4 & & 255 & 14.1 & 27 & 9.1 & & 311 & 11.9 & 43 & 14.7 & & 476 & 11.5 & 86 & 17.9 & & 439 & 13.4 & 116 & 26.3 & \\
\hline \multicolumn{26}{|l|}{ Education } \\
\hline $\begin{array}{l}\text { None or } \\
\text { elementary } \\
\text { school }\end{array}$ & 1,414 & 45.5 & 381 & 26.1 & $<.0001$ & 751 & 44.3 & 186 & 25.4 & $<.0001$ & 897 & 32.1 & 260 & 29.9 & $<.0001$ & 1,138 & 29.9 & 375 & 35.5 & $<.0001$ & 1,294 & 43.8 & 563 & 43.6 & $<.0001$ \\
\hline $\begin{array}{l}\text { Middle or } \\
\text { high school }\end{array}$ & 1,089 & 44.6 & 564 & 52.0 & & 688 & 44.2 & 360 & 53.1 & & 1,224 & 48.8 & 641 & 52.1 & & 1,239 & 48.6 & 643 & 51.9 & & 1,023 & 40.9 & 588 & 59.4 & \\
\hline $\begin{array}{l}\text { University or } \\
\text { higher }\end{array}$ & 222 & 10.0 & 120 & 54.4 & & 183 & 11.6 & 100 & 53.4 & & 475 & 19.1 & 265 & 55.2 & & 567 & 21.5 & 344 & 62.6 & & 420 & 15.3 & 257 & 59.5 & \\
\hline \multicolumn{26}{|c|}{ Marital status } \\
\hline Married & 2,073 & 77.2 & 944 & 46.8 & $<.0001$ & 1,181 & 73.0 & 539 & 45.8 & $<.0001$ & 1,984 & 76.0 & 999 & 50.6 & $<.0001$ & 664 & 18.6 & 199 & 32.0 & $<.0001$ & 2,202 & 81.3 & 1,202 & 55.2 & $<.0001$ \\
\hline not married & 652 & 22.8 & 121 & 19.1 & & 441 & 27.0 & 107 & 27.6 & & 612 & 24.0 & 167 & 29.6 & & 2,280 & 81.4 & 1,163 & 53.2 & & 535 & 18.7 & 206 & 40.8 & \\
\hline \multicolumn{26}{|l|}{$\begin{array}{l}\text { Household } \\
\text { income }\end{array}$} \\
\hline Quartile 1 & 770 & 24.6 & 184 & 24.8 & $<.0001$ & 509 & 30.4 & 109 & 23.8 & $<.0001$ & 666 & 23.0 & 187 & 27.6 & $<.0001$ & 694 & 17.0 & 220 & 33.8 & $<.0001$ & 635 & 20.6 & 252 & 40.7 & $<.0001$ \\
\hline Quartile 2 & 643 & 22.0 & 247 & 39.6 & & 407 & 23.8 & 175 & 44.0 & & 624 & 25.6 & 255 & 40.8 & & 756 & 27.3 & 328 & 47.5 & & 685 & 27.1 & 336 & 51.5 & \\
\hline Quartile 3 & 708 & 27.6 & 345 & 49.0 & & 347 & 22.4 & 170 & 49.1 & & 669 & 26.5 & 343 & 51.2 & & 759 & 28.1 & 382 & 50.9 & & 710 & 27.3 & 391 & 55.0 & \\
\hline Quartile 4 & 604 & 25.8 & 289 & 47.0 & & 359 & 23.5 & 192 & 52.1 & & 637 & 24.9 & 381 & 61.0 & & 735 & 27.6 & 432 & 58.9 & & 707 & 25.0 & 429 & 60.6 & \\
\hline \multicolumn{26}{|l|}{$\begin{array}{l}\text { Health } \\
\text { insurance } \\
\text { type }\end{array}$} \\
\hline $\begin{array}{l}\text { NHI (self- } \\
\text { employed) }\end{array}$ & 1,482 & 53.7 & 597 & 41.3 & $<.0001$ & 748 & 46.2 & 296 & 40.0 & 0.002 & 1,066 & 42.5 & 451 & 44.0 & 0.064 & 1,156 & 39.9 & 524 & 48.4 & 0.001 & 932 & 36.7 & 446 & 49.8 & 0.252 \\
\hline $\begin{array}{l}\mathrm{NHI} \\
\text { (employee) }\end{array}$ & 1,120 & 42.3 & 453 & 42.3 & & 780 & 48.1 & 333 & 44.0 & & 1,412 & 53.5 & 671 & 47.5 & & 1,662 & 56.9 & 805 & 51.1 & & 1,712 & 59.6 & 919 & 54.0 & \\
\hline Medical Aid & 123 & 4.0 & 15 & 9.6 & & 94 & 5.7 & 17 & 22.1 & & 118 & 4.0 & 44 & 35.5 & & 126 & 3.2 & 33 & 28.0 & & 93 & 3.8 & 43 & 56.1 & \\
\hline
\end{tabular}


Table 1 Basic characteristics of the study population and participation rate in cervical cancer screening in women $\geq 30$ years, $1998-2010$ (Continued)

\begin{tabular}{|c|c|c|c|c|c|c|c|c|c|c|c|c|c|c|c|c|c|c|c|c|c|c|c|c|c|}
\hline \multicolumn{26}{|l|}{ Occupation } \\
\hline white collar & 481 & 20.3 & 236 & 48.9 & $<.0001$ & 312 & 19.4 & 165 & 50.5 & 0.002 & 663 & 25.8 & 352 & 52.7 & 0.003 & 628 & 23.9 & 344 & 54.0 & 0.024 & 670 & 27.7 & 369 & 55.0 & 0.233 \\
\hline blue collar & 836 & 23.8 & 290 & 35.4 & & 324 & 20.1 & 124 & 40.9 & & 545 & 18.8 & 232 & 43.6 & & 751 & 21.4 & 315 & 45.3 & & 569 & 21.4 & 282 & 54.0 & \\
\hline others & 1,408 & 55.9 & 539 & 39.6 & & 986 & 60.6 & 357 & 37.8 & & 1,388 & 55.4 & 582 & 42.9 & & 1,562 & 54.7 & 700 & 48.7 & & 1,498 & 50.8 & 757 & 50.5 & \\
\hline \multicolumn{26}{|l|}{$\begin{array}{l}\text { Limitation } \\
\text { in general } \\
\text { activities }\end{array}$} \\
\hline Yes & 709 & 27.4 & 293 & 44.5 & 0.013 & 201 & 12.8 & 62 & 33.7 & 0.045 & 349 & 12.5 & 104 & 30.8 & $<.0001$ & 743 & 21.4 & 279 & 44.1 & 0.019 & 929 & 31.3 & 433 & 49.1 & 0.024 \\
\hline No & 2,016 & 72.6 & 772 & 38.9 & & 1,421 & 87.2 & 584 & 41.9 & & 2,247 & 87.5 & 1,062 & 47.7 & & 2,201 & 78.6 & 1,083 & 50.7 & & 1,808 & 68.7 & 975 & 54.1 & \\
\hline \multicolumn{26}{|l|}{$\begin{array}{l}\text { Perceived } \\
\text { health } \\
\text { status }\end{array}$} \\
\hline $\begin{array}{l}\text { Good or } \\
\text { regular }\end{array}$ & 1,675 & 63.9 & 699 & 43.0 & 0.001 & 1,014 & 63.3 & 456 & 45.5 & $<.0001$ & 1,807 & 70.7 & 891 & 49.8 & $<.0001$ & 1,993 & 71.9 & 956 & 50.2 & 0.165 & 2,029 & 74.8 & 1,093 & 54.1 & 0.016 \\
\hline Bad & 1,050 & 36.1 & 366 & 36.0 & & 608 & 36.7 & 190 & 32.9 & & 789 & 29.3 & 275 & 35.3 & & 951 & 28.1 & 406 & 46.8 & & 708 & 25.2 & 315 & 47.8 & \\
\hline \multicolumn{26}{|l|}{ Smoking } \\
\hline Non-smoker & 2,445 & 89.7 & 1,004 & 42.2 & $<.0001$ & 1,499 & 92.1 & 618 & 42.4 & 0.001 & 2,375 & 90.8 & 1,101 & 46.9 & 0.000 & 2,644 & 88.7 & 1,248 & 49.9 & 0.094 & 2,503 & 90.1 & 1,299 & 52.7 & 0.026 \\
\hline Ex-smoker & 72 & 3.0 & 15 & 23.4 & & 24 & 1.6 & 4 & 17.7 & & 104 & 4.3 & 38 & 53.9 & & 148 & 5.5 & 61 & 49.7 & & 133 & 5.4 & 72 & 60.1 & \\
\hline $\begin{array}{l}\text { Current } \\
\text { smoker }\end{array}$ & 208 & 7.2 & 46 & 25.4 & & 99 & 6.2 & 24 & 25.0 & & 117 & 4.9 & 27 & 28.4 & & 152 & 5.8 & 53 & 38.8 & & 101 & 4.5 & 37 & 40.7 & \\
\hline \multicolumn{26}{|c|}{$\begin{array}{l}\text { Body mass } \\
\text { index }\left(\mathbf{k g} / \mathbf{m}^{2}\right)\end{array}$} \\
\hline$<18.5$ & 106 & 3.8 & 24 & 26.8 & 0.007 & 65 & 3.7 & 21 & 31.0 & 0.165 & 81 & 3.0 & 35 & 42.2 & 0.066 & 123 & 4.3 & 50 & 40.9 & 0.030 & 101 & 3.7 & 45 & 45.5 & 0.000 \\
\hline $18.5 \leq 23$ & 1,076 & 40.4 & 437 & 43.1 & & 601 & 37.9 & 257 & 43.4 & & 4,050 & 41.3 & 493 & 48.0 & & 1,209 & 43.1 & 580 & 52.3 & & 1,150 & 42.5 & 624 & 55.8 & \\
\hline $23 \leq 25$ & 637 & 23.6 & 262 & 41.8 & & 399 & 24.4 & 160 & 42.3 & & 637 & 23.7 & 292 & 47.4 & & 683 & 23.1 & 320 & 50.4 & & 640 & 23.5 & 358 & 56.6 & \\
\hline $25 \leq$ & 906 & 32.2 & 342 & 37.7 & & 557 & 33.9 & 208 & 38.2 & & 828 & 31.9 & 346 & 41.3 & & 929 & 29.5 & 412 & 45.2 & & 846 & 30.3 & 381 & 45.6 & \\
\hline total & 2,725 & 100.0 & 1,065 & 40.5 & & 1,622 & 100.0 & 646 & 40.9 & & 2,596 & 100.0 & 1,166 & 45.5 & & 2,944 & 100.0 & 1,362 & 49.3 & & 2,737 & 100.0 & 1,408 & 52.5 & \\
\hline
\end{tabular}

NHI, National health insurance. 
Table 2 Factors associated with cervical cancer screening among women $\geq 30$ years, 1998-2010

\begin{tabular}{|c|c|c|c|c|c|c|c|c|c|c|}
\hline \multirow{2}{*}{$\begin{array}{l}\text { Variables } \\
\text { Education }\end{array}$} & \multicolumn{2}{|c|}{1998} & \multicolumn{2}{|c|}{2001} & \multicolumn{2}{|c|}{2005} & \multicolumn{2}{|c|}{2008} & \multicolumn{2}{|c|}{2010} \\
\hline & & & & & & & & & & \\
\hline None or elementary school & 1.00 & & 1.00 & & 1.00 & & 1.00 & & 1.00 & \\
\hline Middle or high school & 1.43 & $(1.13-1.82)$ & 1.67 & $(1.18-2.38)$ & 1.15 & $(0.82-1.61)$ & 1.24 & $(0.93-1.66)$ & 1.71 & $(1.24-2.35)$ \\
\hline University or higher & 1.56 & $(1.05-2.30)$ & 1.56 & $(0.94-2.61)$ & 1.00 & $(0.64-1.56)$ & 1.90 & $(1.26-2.87)$ & 1.73 & $(1.12-2.66)$ \\
\hline \multicolumn{11}{|l|}{ Household income } \\
\hline Quartile 1 & 1.00 & & 1.00 & & 1.00 & & 1.00 & & 1.00 & \\
\hline Quartile 2 & 1.22 & $(0.92-1.62)$ & 1.65 & $(1.16-2.34)$ & 1.39 & $(1.00-1.93)$ & 1.09 & $(0.82-1.46)$ & 1.12 & $(0.84-1.49)$ \\
\hline Quartile 3 & 1.52 & $(1.11-2.07)$ & 1.72 & $(1.15-2.59)$ & 1.93 & $(1.44-2.59)$ & 1.05 & $(0.78-1.40)$ & 1.21 & $(0.89-1.66)$ \\
\hline Quartile 4 & 1.31 & $(0.95-1.81)$ & 1.80 & $(1.22-2.68)$ & 2.82 & $(2.01-3.96)$ & 1.34 & $(0.97-1.84)$ & 1.45 & $(1.08-1.94)$ \\
\hline \multicolumn{11}{|l|}{ Occupation } \\
\hline white collar & 1.00 & & 1.00 & & 1.00 & & 1.00 & & 1.00 & \\
\hline blue collar & 0.92 & $(0.69-1.23)$ & 1.08 & $(0.70-1.66)$ & 1.01 & $(0.72-1.41)$ & 1.01 & $(0.78-1.32)$ & 1.29 & $(0.95-1.76)$ \\
\hline others & 1.12 & $(0.87-1.44)$ & 1.02 & $(0.79-1.35)$ & 1.04 & $(0.79-1.35)$ & 1.18 & $(0.93-1.49)$ & 1.20 & $(0.92-1.57)$ \\
\hline
\end{tabular}

Results are presented as adjusted odds ratios and ( $95 \%$ confidence intervals), and adjusted for age, marital status, health insurance type, limitation in general activities, perceived health status, smoking, and body mass index.

We used descriptive statistics for the characteristics of the subjects, and reported the number and percentage for each variable. The participation rates in cervical screening were calculated according to all variables. The odds ratios (ORs) and 95\% confidence intervals (CIs) were calculated to measure the strength of the association between the measured variables and screening participation. We regarded a $p$-value of less than 0.05 as statistically significant.

\section{Results}

Baseline characteristics and participation in cervical cancer screening

The characteristics of the study population and participation rate in cervical cancer screening from 1998 to 2010 are summarized in Table 1 . In this study, the majority of women were married, and enrolled in the NHI program. Most women reported no limitation in their daily activities and were non-smokers. The cervical cancer participation rates increased from $40.5 \%$ in 1998 to $52.5 \%$ in 2010.

Women with the lowest educational status had a participation rate of $26.1 \%$ in 1998 and $43.6 \%$ in 2010 . However, women with the highest educational status reported a higher participation rate of 54.4\% in 1998 and $59.5 \%$ in 2010 . Women in the lowest household income group had a participation rate of $24.8 \%$ in 1998 and $40.7 \%$ in 2010 . Women in the highest household income group had a participation rate of $47.0 \%$ in 1998 and $60.6 \%$ in 2010 .

Figure 1 indicates that the gaps between the highest and lowest educational status and income groups narrowed during the 12 years in Korea.

\section{Factors associated with cervical cancer screening} participation

Table 2 shows the results of the multivariate logistic regression analysis for cancer screening. Of the socioeconomic factors considered, higher educational level was found to be associated with a higher OR in 1998, 2001, 2008, and 2010. Compared with the lowest educational level, the adjusted ORs of the highest education level were 1.56 (95\% CI: 1.05-2.30), 1.90 (95\% CI: $1.26-$ 2.87 ), and 1.73 (95\% CI: $1.12-2.66)$ in 1998, 2008, and 2010. A higher household income was also found to be associated with a higher OR in 2001, 2005, and 2010. Compared with the lowest household income level, the adjusted ORs of the highest household income level were 1.80 (95\% CI: 1.22-2.68), 2.82 (95\% CI: 2.01-3.96), and 1.45 (95\% CI: $1.08-1.94)$ in 2001, 2005, and 2010, respectively.

Among the other variables, age was a statistically significant factor which was inversely related to cervical cancer screening during 1998-2010, suggesting that older women were less likely to participate in screening. Although marital status, health insurance type, and smoking status were statistically significant factors in one or two study years, their significance was either not as strong as socioeconomic status or somewhat inconsistent.

\section{Discussion}

The objective of this study was to examine the change in rates of participation in cervical cancer screening among Korean women from 1998 to 2010, and to test whether socioeconomic disparities in cervical cancer screening decreased, stayed the same, or worsened. We observed that the participation rate of Korean women 30 years or older in cervical cancer screening was $40.5 \%$ in 1998 , 

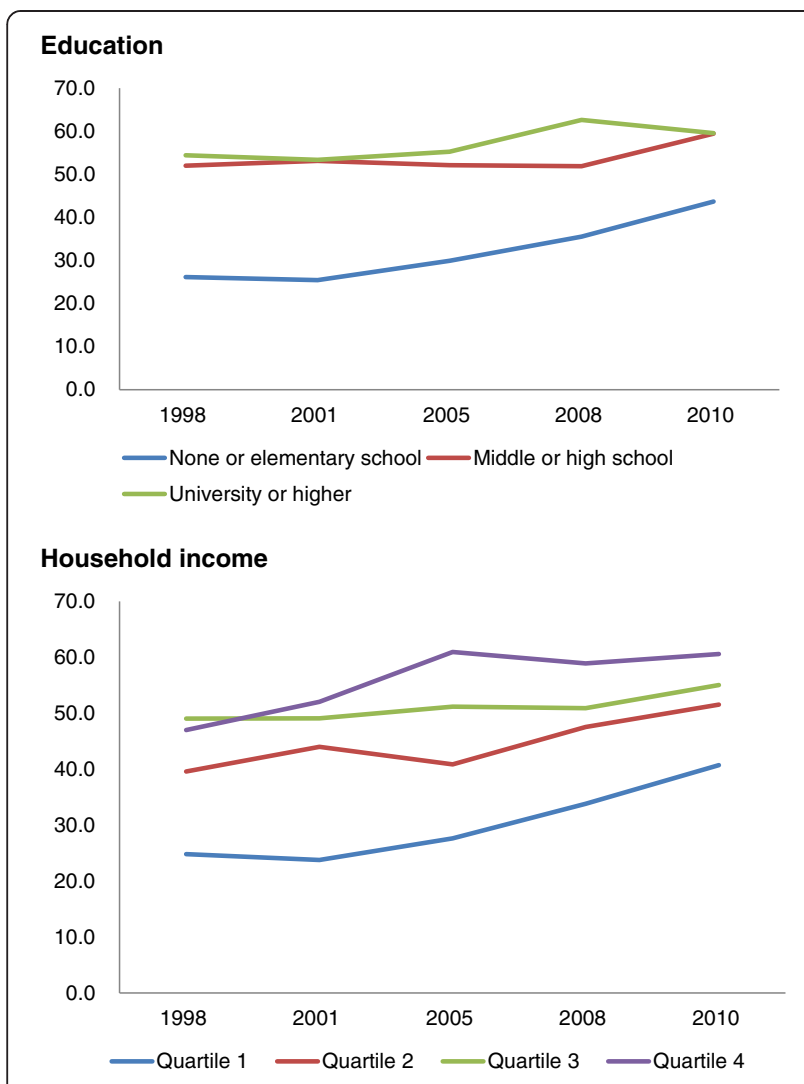

\section{Occupation}

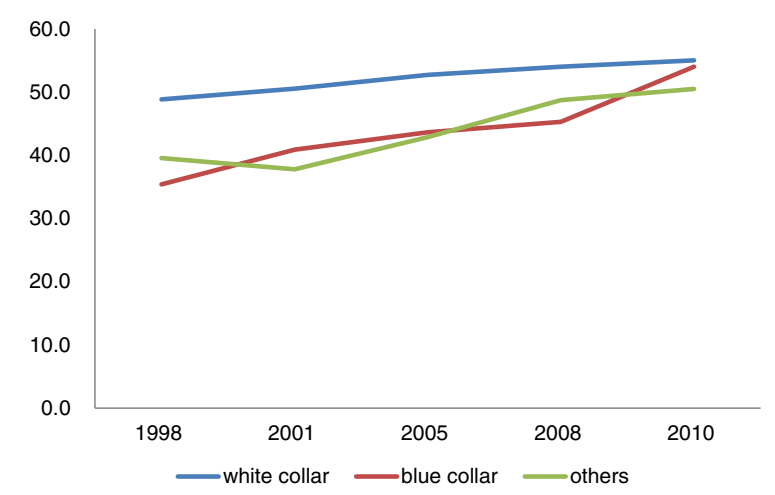

Figure 1 Cervical cancer screening rate by education and household income and occupation, 1998-2010.

$40.9 \%$ in $2001,45.5 \%$ in $2005,49.3 \%$ in 2008 , and $52.5 \%$ in 2010. Although this suggests that there has been steady progress in improving the cervical cancer screening rate over the past decade, there is certainly room for improvement because the rate is still around 50\%, significantly lower than in other economically developed countries. There were particularly low rates of participation in women with the lowest educational level $(26.1 \%$ in $1998,25.4 \%$ in $2001,29.9 \%$ in $2005,35.5 \%$ in 2008 , and $43.6 \%$ in 2010), and in women with the lowest household income $(24.8 \%$ in $1998,23.8 \%$ in $2001,27.6 \%$ in $2005,33.8 \%$ in 2008 , and $40.7 \%$ in 2010 ). Importantly, the participation rates of women in the lowest education and income groups markedly improved over the years, and the gaps with the highest education and income groups were reduced. The results of our study suggest important policy implications for policymakers to improve participation rates and to further reduce the difference in rates according to socioeconomic status.

Previous studies have found educational level to be a significant predictor of cervical cancer screening participation $[23,24]$, and educational level has a huge effect on knowledge of the advantages of participation in cervical cancer screening after controlling for other covariates $[25,26]$. The results of our study are consistent with previous studies in showing that educational level was significantly associated with participation in cervical cancer screening among Korean women, and, more importantly, that the association lasted over a decade. It is worth noting that two previous studies found that disparities in cancer screening by household income were improved, but there was no improvement for disparities in cancer screening by education level among Korean women [27,28].

Previous studies also found that household income was a significant predictor of cervical cancer screening participation $[28,29]$. It was suggested that to improve cancer screening participation rates in lower income individuals, a primary health care intervention such as an organized program of cervical screening that focuses on deprived groups is needed [30]. Therefore, it is important to keep monitoring how public health policies impact on participation rates over time, such as that which expanded the scope of free cervical cancer examinations to women in the lower $50 \%$ income bracket of households [13].

Our study has several limitations. First, although this study examined data in a 12-year study period, it was based on pooled cross-sectional data, from which we cannot detect a causal relationship. Second, the KNHANES is based on self-reported responses to participation in cervical cancer screening, which may raise acquiescence bias or recall bias. To minimize recall bias in collecting the data, the KNHANES was conducted by educated and trained interviewers. However, we acknowledge that the survey was unable to perform a cross-check with medical records. Therefore, recall and acquiescence (social desirability) bias can remain, and may result in misclassification. Although misclassification can be either random or nonrandom, we believe that, in a large nationwide survey such as KNHANES, it was random. Therefore, potential recall bias may lead to an association toward null, and an underestimate of the true association. A previous study also pointed out a similar possibility of underestimation of the actual participation rate [31-33]. Finally, other factors that may be significant determinants of cervical cancer screening participation were not included in the current 
study. For example, there was no control for family history of cervical cancer, age at first sexual intercourse, and knowledge and attitudes about cervical cancer risk factors and benefits of the Pap test.

\section{Conclusion}

In conclusion, in the analysis of nationally representative data over a decade, we found that there was an increase in participation in cervical cancer screening programs by Korean women from $40.5 \%$ in 1998 to $52.5 \%$ in 2010 , though the rate remained lower than in other developed countries. We also observed that despite the overall increase in screening rates, socioeconomic disparities continued to exist. Although screening rates in women with the lowest educational levels and household incomes improved over the period, they remained lower than in women of the highest education and income groups.

These results demonstrate the need for more aggressive interventions and policies to improve participation in cervical cancer screening especially for those at a lower income and education level. Analyses of cervical cancer screening rates by measures of household income, educational level, and other factors over the long term may help policy-makers to better direct their resources to those of greatest need. Ensuring that free cervical cancer screening programs or other public health programs remain available for women in the lower income groups can lead us closer to national screening goals, yet policies or campaigns still need to address disparities in cervical cancer screening according to educational level.

\section{Competing interests}

The authors declared that they have no competing interest.

\section{Authors' contributions}

All the authors developed the idea for the study. ML analyzed the data and wrote the first draft of the paper. ECP and HSJ participated in the design and coordination. JAK and KBY contributed to interpreting the data. THK contributed to developing and writing subsequent drafts. All authors approved the final manuscript. THK is the guarantor.

\section{Acknowledgments}

This study was funded by a grant from the Korean Foundation for Cancer Research (7-2011-0489).

\section{Author details \\ 'Department of Public Health, Institute of Health Services Research, Yonsei University, Seoul, Korea. ${ }^{2}$ Department of Preventive Medicine and Public Health, Institute of Health Services Research, College of Medicine, Yonsei University, Seoul, Korea. ${ }^{3}$ Graduate School of Public Health, Institute of Health Services Research, College of Medicine, Yonsei University, Seoul, Korea.}

Received: 9 July 2012 Accepted: 21 May 2013

Published: 6 June 2013

\section{References}

1. Korea Ministry of Health \& Welfare, Center NC: Cancer facts \& figures 2010 in the Republic of Korea. Seoul (Korea): Ministry of Health \& Welfare; 2010.

2. Whynes DK, Philips Z, Avis M: Why do women participate in the English cervical cancer screening programme? J Health Econ 2007, 26(2):306-325.
3. Abdullah F, Su TT: Enhancement of the cervical cancer screening program in Malaysia: a qualitative study. Asian Pac J Cancer Prev 2010, 11(5):1359-1366.

4. Lee J, Seow A, Ling SL, Peng LH: Improving adherence to regular pap smear screening among Asian women: a population-based study in Singapore. Health Educ Behav 2002, 29(2):207-218.

5. Ibekwe CM, Hoque ME, Ntuli-Ngcobo B: Perceived benefits of cervical cancer screening among women attending Mahalapye District Hospital, Botswana. Asian Pac J Cancer Prev 2010, 11(4):1021-1027.

6. Greenlee RT, Murray T, Bolden S, Wingo PA: Cancer statistics, 2000. CA Cancer J Clin 2000, 50(1):7-33.

7. Taylor R, Morrell S, Mamoon H, Wain G, Ross J: Decline in cervical cancer incidence and mortality in New South Wales in relation to control activities (Australia). Cancer Causes Control 2006, 17(3):299-306.

8. Paley PJ: Screening for the major malignancies affecting women: current guidelines. Am J Obstet Gynecol 2001, 184(5):1021-1030.

9. Watkins MM, Gabali C, Winkleby M, Gaona E, Lebaron S: Barriers to cervical cancer screening in rural Mexico. Int J Gynecol Cancer 2002, 12(5):475-479.

10. National Cancer Information Center: National Cancer Control Program. [http://www.cancer.go.kr/mbs/cancer/index.jsp]

11. International Agency for Research on Cancer: Screening for cancer of the uterine cervix. Lyon: International Agency for Research on Cancer; 1986.

12. Sung NY, Park EC, Shin HR, Choi KS: Participation rate and related socio-demographic factors in the national cancer screening program. J Prev Med Public Health 2005, 38(1):93-100.

13. Kwak MS, Park EC, Bang JY, Sung NY, Lee JY, Choi KS: Factors associated with cancer screening participation, Korea. J Prev Med Public Health 2005, 38(4):473-481

14. Adams EK, Breen N, Joski PJ: Impact of the national breast and cervical cancer early detection program on mammography and Pap test utilization among white, hispanic, and african american women: 1996-2000. Cancer 2007, 109(2 Suppl):348-358.

15. Fukuda Y, Nakamura K, Takano T: Reduced likelihood of cancer screening among women in urban areas and with low socio-economic status: a multilevel analysis in Japan. Public Health 2005, 119(10):875-884.

16. Moser K, Patnick J, Beral V: Inequalities in reported use of breast and cervical screening in Great Britain: analysis of cross sectional survey data. BMJ 2009, 338:b2025-b2025.

17. Martin-Lopez R, Hernandez-Barrera V, de Andres AL, Carrasco-Garrido P, de Miguel AG, Jimenez-Garcia R: Trend in cervical cancer screening in Spain (2003-2009) and predictors of adherence. Eur J Cancer Prev 2012, 21(1):82-88.

18. Lee K, Lim HT, Hwang SS, Chae DW, Park SM: Socio-economic disparities in behavioural risk factors for cancer and use of cancer screening services in korean adults aged 30 years and older: the third korean national health and nutrition examination survey, 2005 (KNHANES III). Public Health 2010, 124(12):698-704.

19. Martinez-Huedo MA, Lopez de Andres A, Hernandez-Barrera V, CarrascoGarrido P, Martinez Hernandez D, Jimenez-Garcia R: Adherence to breast and cervical cancer screening in spanish women with diabetes: associated factors and trend between 2006 and 2010. Diabetes Metab 2012, 38(2):142-148.

20. Park MJ, Park EC, Choi KS, Jun JK, Lee HY: Sociodemographic gradients in breast and cervical cancer screening in Korea: the korean national cancer screening survey (KNCSS) 2005-2009. BMC Cancer 2011, 11:257.

21. Wang JH, Sheppard VB, Schwartz MD, Liang W, Mandelblatt JS: Disparities in cervical cancer screening between asian american and Non-hispanic white women. Cancer Epidemiol Biomarkers Prev 2008, 17(8):1968-1973.

22. Jang SN, Cho SI, Hwang SS, Jung-Choi K, Im SY, Lee JA, Kim MK: Trend of socioeconomic inequality in participation in cervical cancer screening among Korean women. J Prev Med Public Health 2007, 40(6):505-511.

23. Nene B, Jayant K, Arrossi S, Shastri S, Budukh A, Hingmire S, Muwonge R, Malvi S, Dinshaw K, Sankaranarayanan R: Determinants of womens participation in cervical cancer screening trial, Maharashtra. India. Bull World Health Organ 2007, 85(4):264-272.

24. Shin JH, Kim DW, Cho SH, Moon H, Kim DS, Choi BY: The knowledge and attitude to the uterine cervix cancer and screening program in the patients with cervical cancer and recipients of pap smear. Korean J ObstetGynecol 1993, 36(2):215-225.

25. Tsui J, Tanjasiri SP: Cervical cancer screening among Thai women in Northern California. J Womens Health (Larchmt) 2008, 17(3):393-401. 
26. Taylor VM, Yasui Y, Burke N, Nguyen T, Acorda E, Thai H, Qu P, Jackson JC: Pap testing adherence among Vietnamese American women. Cancer Epidemiol Biomarkers Prev 2004, 13(4):613-619.

27. Chun EJ, Jang SN, Cho SI, Cho Y, Moon OR: Disparities in participation in health examination by socio-economic position among adult Seoul residents. J Prev Med Public Health 2007, 40(5):345-350.

28. Kwak MS, Choi KS, Spring BJ, Park S, Park E-C: Predicting the stages of adoption of cervical cancer screening among Korean women. Prev Med 2009, 49(1):48-53.

29. Paskett ED, McLaughlin JM, Reiter PL, Lehman AM, Rhoda DA, Katz ML, Hade EM, Post DM, Ruffin MT: Psychosocial predictors of adherence to risk-appropriate cervical cancer screening guidelines: a cross sectional study of women in Ohio Appalachia participating in the community awareness resources and education (CARE) project. Prev Med 2010, 50(1-2):74-80.

30. Baker D, Middleton E: Cervical screening and health inequality in England in the 1990s. J Epidemiol Community Health 2003, 57(6):417-423.

31. Messina CR, Kabat GC, Lane DS: Perceptions of risk factors for breast cancer and attitudes toward mammography among women who are current, ex- and non-smokers. Women Health 2002, 36(3):65-82.

32. Clark MA, Rakowski W, Ehrich B: Breast and cervical cancer screening: associations with personal, spouse's, and combined smoking status. Cancer Epidemiol Biomarkers Prev 2000, 9(5):513-516.

33. McPhee SJ, Nguyen TT, Shema SJ, Nguyen B, Somkin C, Vo P, Pasick R: Validation of recall of breast and cervical cancer screening by women in an ethnically diverse population. Prev Med 2002, 35(5):463-473.

doi:10.1186/1471-2458-13-553

Cite this article as: Lee et al:: Socioeconomic disparity in cervical cancer screening among Korean women: 1998-2010. BMC Public Health 2013 13:553.

\section{Submit your next manuscript to BioMed Central and take full advantage of:}

- Convenient online submission

- Thorough peer review

- No space constraints or color figure charges

- Immediate publication on acceptance

- Inclusion in PubMed, CAS, Scopus and Google Scholar

- Research which is freely available for redistribution 